\title{
Introduction of leukotriene receptor antagonists in Manitoba
}

\author{
C Macie $M D^{1}$, K Wooldrage $B S c^{1}$, J Manfreda $M D^{1,2}, N R$ Anthonisen MD PhD ${ }^{1}$
}

\begin{abstract}
C Macie, K Wooldrage, J Manfreda, NR Anthonisen. Introduction of leukotriene receptor antagonists in Manitoba. Can Respir J 2006;13(2):94-98.
\end{abstract}

Patient characteristics and prescribing patterns during the introduction of leukotriene receptor antagonists (LTRA) in Manitoba are described using the provincial health database. Residents of Manitoba with asthma, chronic obstructive pulmonary disease, bronchitis or claims for respiratory medications were identified. Six thousand forty-one of 160,626 (3.8\%) patients received LTRA; the likelihood of receiving LTRA increased if a patient was younger than 15 years, lived in a rural locale, had asthma, had frequent physician visits or used inhaled corticosteroids. Subsequent prescriptions (68\%) were associated with the number of physician visits and inhaled corticosteroid use, which were thought to be indexes of severity. Patients, especially children, who received more than five prescriptions showed evidence of increased asthma control, but there was little evidence of benefit in less selected patient groups due, at least in part, to poor compliance with all respiratory drugs.

Key Words: Asthma; Inhaled corticosteroids; Leukotriene receptor antagonists; Population-based

\section{Introduction des antagonistes des récepteurs des leucotriènes au Manitoba}

\begin{abstract}
À partir de la base de données du système de santé provincial, on décrit ici les caractéristiques des patients et les modes habituels de prescription au moment où les antagonistes des récepteurs des leucotriènes (ARLT) ont fait leur entrée au Manitoba. Les résidents du Manitoba qui souffrent d'asthme, de maladie pulmonaire obstructive chronique, de bronchite ou qui réclament le remboursement de médicaments pour des affections respiratoires ont dans un premier temps été identifiés. Sur les 160626 patients ainsi recensés, 6041 (3,8\%) ont reçu des ARLT. La probabilité de recevoir un ARLT augmentait si un patient avait moins de 15 ans, s'il vivait en région rurale, s'il souffrait d'asthme, s'il consultait souvent le médecin ou s'il utilisait des corticostéroïdes par inhalation. Le renouvellement des ordonnances (68\%) a été associé au nombre de visites médicales et à l'utilisation des corticostéroïdes par inhalation, deux éléments considérés comme des indices de la gravité de l'état de santé des patients. Ces derniers, et particulièrement les enfants ayant reçu plus de cinq ordonnances, montraient les signes d'un asthme mieux maîtrisé, mais les avantages ont semblé moins perceptibles dans les groupes de patients moins sélectionnés, et ce, du moins en partie, en raison d'une mauvaise observance thérapeutique.
\end{abstract}

$\mathrm{R}^{\mathrm{cos}}$ esearch into the pathogenesis of asthma has led to the development of specific treatments. Inflammatory cells in lung tissue release a variety of mediators, including cysteinyl leukotrienes. These leukotrienes give rise to bronchoconstriction, mucus secretion, increased vascular permeability, smooth muscle hypertrophy and inflammatory cell infiltration - events similar to those associated with asthma (1-3). Leukotriene receptor antagonists (LTRA) block the interaction of cysteinyl leukotrienes with their receptor, and ameliorate asthma symptoms, improve lung function, reduce exacerbations and lower the use of rescue beta-agonist treatments in patients with persistent asthma $(3,4)$.

Although inhaled corticosteroids (ICS) represent the gold standard in asthma treatment (5), LTRA offer an alternative option to prevent exacerbations in mild asthma, and may be useful as an add-on therapy in patients that do not achieve adequate control with ICS and short-acting beta-agonists $(6,7)$.

LTRA are the only new class of drugs for the treatment of asthma developed in the past 20 years. They were introduced in Manitoba in December 1997. In a large, unselected population, we examined prescribing patterns of LTRA and the characteristics of patients to whom LTRA were prescribed. We also tried to assess their effect on disease control.

\section{METHODS}

The province of Manitoba (population of approximately 1.1 million) has a universally accessible single-payer health insurance plan administered by the provincial government. For payment, a physician submits a claim describing services provided, including the patient's diagnosis. For research purposes, the Manitoba Population Health Research Repository contains the provincial population records of physician contacts, hospital separations, vital statistics and the Drug Programs Information Network linked by a unique anonymized identifier. The same identifier links these databases to the Population Registry, which provides information about the duration of health insurance coverage for each permanent resident of Manitoba. Coverage ends with moving out of the province or with death.

The Drug Programs Information Network database was created by retail pharmacies, where the dispensed prescription is entered into the database in real time to facilitate screening for inappropriate use, such as drug interactions, and copayment for medication. This database contains information about the cost of the prescription and the presence of a supplemental insurance plan at the point of purchase, as well as information about the drug dispensed - specifically, the anatomical therapeutic chemical code, the drug identification number, the date and quantity dispensed, and the number of days for which the drug was supplied (8). 
Manitoba residents with a claim for drugs for obstructive airways disease (anatomical therapeutic chemical code R03) between December 1, 1997, and December 31, 2000, were identified. These patients were linked to physician claims, hospitalizations and vital statistics databases to identify events labelled with the following International Classification of Diseases, 9th Revision (9) codes: bronchitis (acute bronchitis/bronchiolitis: code 466; not otherwise specified bronchitis: code 490); asthma (code 493); and chronic obstructive pulmonary disease (COPD) (chronic bronchitis: code 491; emphysema: code 492; chronic airflow obstruction: code 496).

Urban residence was arbitrarily defined as Winnipeg, the capital of Manitoba, with approximately 650,000 residents, while the remaining population, living in towns with no more than 30,000 residents, was defined as rural.

To identify characteristics of patients who received LTRA, for each LTRA recipient, 10 controls were randomly selected from the pool of patients who received another respiratory drug (ie, ICS, bronchodilators or theophylline) in the same month and who had a physician claim for a respiratory diagnosis in the 14 days before filling the prescription. This method identified patients for whom a prescribing decision was made rather than those receiving a routine refill of an existing prescription, so that the control group had a similar opportunity to receive LTRA. The two groups were compared with respect to demographics and health records over the two years before the prescription.

LTRA recipients who had one year follow-up data were identified. Those who had only one prescription filled versus those who had more than one filled were compared with respect to demographics and health records over the two years before the first prescription. These patients were further divided into three groups depending on the number of LTRA prescriptions filled in the year following the first prescription, and the impact of LTRA use was examined by comparing health records one year before the prescription with those one year after. Impact was assessed in terms of the use of other respiratory drugs and treatment failures. Treatment failures were defined as either hospitalization for asthma, COPD or bronchitis, or unscheduled physician visits for the same diagnoses. Unscheduled visits were defined as weekend visits or two visits within seven days. The effectiveness of LTRA in comparison with ICS for control of obstructive airways disease was assessed by examining the time from drug dispensation to failure (defined above). This was carried out for 30- and 365-day periods using survival analysis. Subsets of LTRA subjects with appropriate follow-up data were examined. For each, a control was selected that had filled a prescription for ICS in the same month as the case subject received LTRA, and who had the same sex, age (within five years), residence (three character postal code) and duration of follow-up. Controls also had to have had a physician visit within two weeks before filling the ICS prescription. If there was more than one eligible individual, then the control was selected randomly, and if there was no matched control, then the LTRA subject was dropped from the analysis.

Descriptive statistical methods were used. For comparison of continuous variables, the $t$ test or Wilcoxon's test was used as appropriate. Categorical variables were compared using the $\chi^{2}$ test. Characteristics of those to whom an LTRA prescription was dispensed (first or continuous) were identified by using logistic regression analysis. Failure rates were analyzed by using the Cox proportional hazards model. Confidence intervals $(95 \% \mathrm{CI})$ were calculated for odds ratios and hazard ratios as appropriate. Results were considered statistically significant at $\mathrm{P}<0.05$. Analyses were conducted with SAS software (version 8.2, SAS Institute Inc, USA).

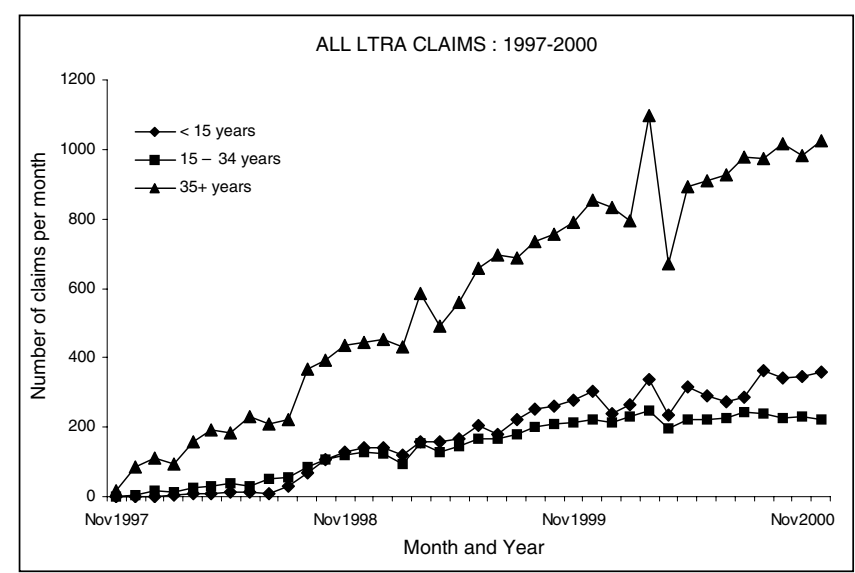

Figure 1) Monthly prescription claims for leukotriene receptor antagonists (LTRA) by age group

The Ethics Board of the University of Manitoba (Winnipeg, Manitoba) and the Access and Confidentiality Committee of Manitoba Health approved the study.

\section{RESULTS}

In December 1997, zafirlukast (Accolate, AstraZeneca, Canada), was the first LTRA introduced in Manitoba; it is dosed twice daily. Montelukast (Singulair, Merck Frosst, Canada), a once-aday drug, became available in September 1998 in both adult and pediatric formulations. Between December 31, 1997, and December 31, 2000, LTRA were dispensed to 6041 Manitoba residents, totalling 33,974 prescriptions. Figure 1 shows the increase in LTRA claims after the introduction. At the end of the year 2000, the number of prescriptions was approximately 1500 per month. With the introduction of montelukast, the prescribing and dispensing of zafirlukast levelled off. At the end of the year 2000, zafirlukast represented approximately $25 \%$ of the claims. Prescribing to those younger than 15 years started with the introduction of montelukast.

The presence of a supplemental insurance plan for prescription drugs had little effect on the first or repeat LTRA prescription rate.

There were 160,626 patients who received respiratory drugs during the study period, and LTRA were dispensed to $6041(3.8 \%)$ of them. Table 1 shows the odds of being dispensed LTRA after adjustment for the effects of all variables in the model. Factors increasing the likelihood of receiving LTRA were pediatric age group, living in a rural locale, having any diagnosis other than COPD (especially asthma) and an increased number of physician visits. The previous use of ICS, theophylline or other respiratory drugs increased the likelihood of receiving LTRA, whereas previous use of beta-agonists appeared to decrease the likelihood when adjusted for the effects of other variables. Hospitalization for COPD or bronchitis also decreased the likelihood of receiving LTRA.

Data for the year following the prescription of LTRA were available for 3791 patients. A second prescription was dispensed to 2580 (68\%) of them. Those aged 15 to 34 years were less likely to continue on LTRA compared with those younger than 15 years. In multivariate analyses, second prescriptions were more common in those with two or more physician visits and who used respiratory drugs (ie, beta-agonists and ICS) during the two years before receiving the first prescription of 
TABLE 1

Characteristics of patients to whom leukotriene receptor antagonists (LTRA) were dispensed

\begin{tabular}{|c|c|c|c|}
\hline & $\begin{array}{l}\text { Receiving } \\
\text { LTRA (\%) }\end{array}$ & $\begin{array}{c}\text { Controls } \\
(\%)\end{array}$ & $\begin{array}{l}\mathrm{OR}(95 \% \mathrm{Cl}) \\
\text { multivariate }\end{array}$ \\
\hline Total (n) & 6041 & 60,410 & \\
\hline \multicolumn{4}{|l|}{ At time of LTRA claim } \\
\hline \multicolumn{4}{|l|}{ Sex } \\
\hline Female & 52.4 & 51.5 & 1.0 \\
\hline Male & 47.6 & 48.5 & $0.97(0.92-1.02)$ \\
\hline \multicolumn{4}{|l|}{ Age (years) } \\
\hline 0 to 14 & 24.0 & 17.6 & 1.0 \\
\hline 15 to 34 & 19.2 & 18.9 & $0.77(0.71-0.84)$ \\
\hline 35 and older & 56.9 & 63.6 & $0.86(0.80-0.93)$ \\
\hline \multicolumn{4}{|l|}{ Location } \\
\hline Rural & 43.5 & 39.6 & 1.0 \\
\hline Urban & 56.5 & 60.4 & $0.78(0.74-0.83)$ \\
\hline \multicolumn{4}{|c|}{ Two years before LTRA claim } \\
\hline \multicolumn{4}{|c|}{ Diagnosis } \\
\hline COPD & 5.0 & 15.8 & 1.0 \\
\hline Asthma & 70.0 & 47.4 & $5.24(4.57-6.00)$ \\
\hline Asthma/COPD & 13.6 & 10.9 & $3.26(2.84-3.75)$ \\
\hline Bronchitis & 4.0 & 9.9 & $1.69(1.40-2.03)$ \\
\hline None & 7.4 & 16.0 & $2.57(2.15-3.07)$ \\
\hline \multicolumn{4}{|l|}{ Physician visits } \\
\hline 0 to 1 & 18.0 & 32.8 & 1.0 \\
\hline 2 to 3 & 23.0 & 24.0 & $1.47(1.31-1.60)$ \\
\hline 4 to 9 & 36.6 & 29.1 & $2.03(1.84-2.24)$ \\
\hline 10 or more & 22.4 & 14.1 & $3.06(2.73-3.44)$ \\
\hline Beta-agonists & 80.5 & 77.4 & $0.65(0.60-0.70)$ \\
\hline Inhaled corticosteroids & 71.6 & 60.4 & $1.11(1.03-1.19)$ \\
\hline Ipratropium bromide & 19.4 & 23.1 & $1.00(0.92-1.09)$ \\
\hline Theophylline & 12.2 & 10.7 & $1.12(1.02-1.22)$ \\
\hline Other respiratory drugs & 4.9 & 1.9 & $1.96(1.71-2.24)$ \\
\hline \multicolumn{4}{|l|}{ Hospitalization* } \\
\hline None & 89.4 & 90.5 & 1.0 \\
\hline COPD & 3.2 & 5.2 & $0.75(0.63-0.88)$ \\
\hline Asthma & 7.0 & 3.3 & $1.08(0.96-1.22)$ \\
\hline Bronchitis & 0.5 & 1.0 & $0.33(0.23-0.49)$ \\
\hline
\end{tabular}

${ }^{*}$ Hospitalization is taken as the most recent hospitalization in the two-year time period. COPD Chronic obstructive pulmonary disease

LTRA. Continuation of therapy was not related to sex, residence, diagnosis or hospitalization (data not shown).

The year before the first LTRA prescription was compared with the year after prescription in groups separated according to persistence in LTRA use. Patients who received a single LTRA prescription had increased use of inhaled steroids and ipratropium, and no change in failure rates in the following year. On the other hand, those who received more than five LTRA prescriptions in the following year had reduced use of inhaled steroids and significantly reduced failure rates. These results were age dependent, with the most striking results in children (Tables 2 and 3). Although persistent use of LTRA was associated with reduced use of ICS in all three age groups, it was significant only in the youngest group (Table 2). Failure rates were similarly decreased in children with persistent LTRA use, and to some extent in those aged 15 to 34 years (Table 3). Eliminating patients who had diagnoses other than asthma reduced failure rates in the oldest group, but did not provide evidence that persistent LTRA use improved control in this group.
Of the 6041 patients who received LTRA (Table 1), 5885 (97.4\%) had follow-up data for 30 days. A matched control that received ICS was identified for 5419 (92.1\%) of these patients. The time to failure in the 30-day observation period did not differ between groups, although failure rates exceeded 4.4\%. However, 1569 (29.0\%) of the LTRA patients also received ICS. Therefore, patients given LTRA only, ICS only, and both LTRA and ICS were further compared. Results, after adjustment for prior physician visits, diagnostic group and drug use, are shown in Table 4. There was a nonsignificant tendency for lower failure rates in patients receiving both LTRA and ICS compared with those receiving only LTRA. There was less of a difference between those receiving only LTRA or only ICS. The same was true when the analysis was restricted to patients with a diagnosis of asthma (data not shown).

For the 3791 patients who received LTRA and had data for the year thereafter, 3487 (92.2\%) matched controls were found that received ICS. They differed in that the controls were more likely to have COPD, had fewer physician visits and were less likely to be receiving respiratory drugs. Analysis of time to failure in these groups was complicated by poor adherence to the drugs. Slightly more than $33 \%$ of the LTRA patients renewed their prescriptions at the end of the first month, and at 12 months, approximately $24 \%$ of the original group was still using the drugs. Of those initially given ICS, only $24 \%$ renewed their prescription at one month, and at 12 months, $21 \%$ were still using ICS. To account for this finding, time to failure analysis entered the drugs in a time-dependent fashion; that is, when a failure occurred, it was ascertained whether the patient had been taking drugs during the preceding month. Time to failure over one year did not differ among those given LTRA only, ICS only, and both LTRA and ICS; indeed, results were similar in patients who were not taking any of these drugs at the time of failure. This was also true after adjustment for diagnosis, the number of physician visits and drug use for the preceding two years.

\section{DISCUSSION}

The present study had a number of important strengths related to the inclusiveness and detail of our database. It included all unselected patients from the total population of Manitoba. We were able to enumerate claims for all respiratory medications, hospitalizations and physician visits received by each patient with obstructive airways disease.

Our study does have some limitations. We relied on physician claims for diagnoses, with no objective evidence of obstructive airways disease. We equated drug use with drug dispensing, and were not able to confirm that patients actually used the medications that they received. Low rates of compliance with dispensed therapy have been reported for asthma and other chronic diseases (10). Our definition of treatment failure left something to be desired. Specifically, we did not have access to hospital emergency visits as a measure of asthma control because these were not available in the database; most exacerbations requiring treatment in an emergency department do not result in hospitalization (11). We attempted to capture unscheduled physician visits by enumerating visits on weekends and the second visit within a seven-day period. We could not assess the use of short-acting beta-agonists as rescue therapy because long-acting beta-agonists were introduced shortly before the study began. Long-acting beta-agonist use increased throughout our study period, clearly replacing shortacting agents to an unknown extent. 
TABLE 2

Comparison of drug use in the year before and the year after the first prescription of leukotriene receptor antagonists (LTRA) by age group and the number of LTRA prescriptions

\begin{tabular}{|c|c|c|c|c|c|c|c|c|c|}
\hline & \multicolumn{3}{|c|}{1 LTRA prescription } & \multicolumn{3}{|c|}{2 to 5 LTRA prescriptions } & \multicolumn{3}{|c|}{ >5 LTRA prescriptions } \\
\hline & Before (\%) & After (\%) & $\mathbf{P}$ & Before (\%) & After (\%) & $\mathbf{P}$ & Before (\%) & After (\%) & $\mathbf{P}$ \\
\hline \multicolumn{10}{|l|}{ Ages 0 to 14 years } \\
\hline Beta-agonists & 54.3 & 50.7 & 0.30 & 66.0 & 61.7 & 0.18 & 83.8 & 76.8 & 0.02 \\
\hline Inhaled corticosteroids & 43.3 & 45.4 & 0.49 & 52.7 & 55.0 & 0.42 & 78.2 & 65.9 & $<0.001$ \\
\hline Ipratropium bromide & 0.7 & 1.4 & 0.16 & 1.3 & 1.3 & 1.00 & 1.8 & 1.1 & 0.41 \\
\hline \multicolumn{10}{|l|}{ Ages 15 to 34 years } \\
\hline Beta-agonists & 76.0 & 79.1 & 0.28 & 83.5 & 81.9 & 0.54 & 89.9 & 86.7 & 0.16 \\
\hline Inhaled corticosteroids & 54.4 & 58.2 & 0.27 & 64.1 & 63.3 & 0.82 & 73.4 & 69.3 & 0.25 \\
\hline Ipratropium bromide & 3.0 & 5.3 & 0.11 & 5.9 & 4.2 & 0.25 & 9.6 & 7.3 & 0.27 \\
\hline \multicolumn{10}{|l|}{ Ages 35 years and older } \\
\hline Beta-agonists & 73.0 & 71.5 & 0.37 & 79.6 & 77.5 & 0.21 & 82.9 & 83.0 & 0.93 \\
\hline Inhaled corticosteroids & 62.3 & 66.4 & 0.02 & 73.7 & 73.0 & 0.66 & 80.4 & 77.8 & 0.06 \\
\hline Ipratropium bromide & 24.8 & 27.3 & 0.06 & 25.0 & 28.7 & 0.01 & 30.9 & 32.5 & 0.19 \\
\hline
\end{tabular}

TABLE 3

Comparison of failures in the year before and the year after the first prescription of leukotriene receptor antagonists (LTRA) by age group and the number of LTRA prescriptions

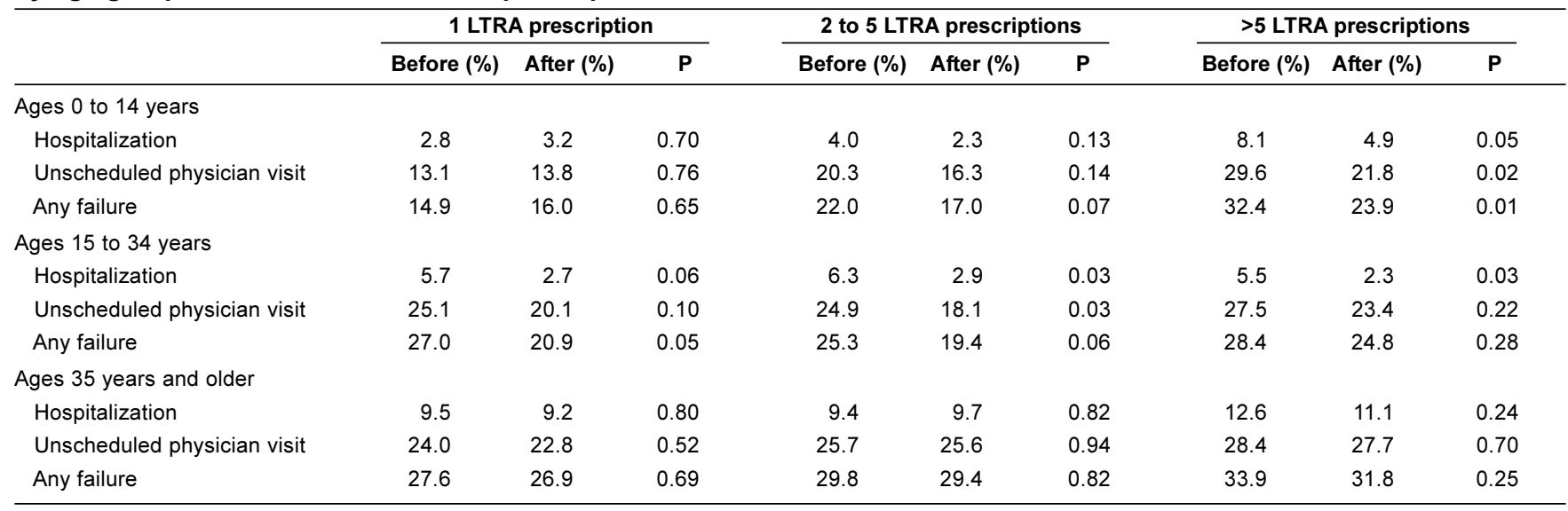

TABLE 4

Effectiveness analysis

\begin{tabular}{|c|c|c|c|c|c|c|}
\hline & \multicolumn{2}{|c|}{ LTRA only $(n=3850)$} & \multicolumn{2}{|c|}{ LTRA plus ICS ( $\mathrm{n}=1569)$} & \multicolumn{2}{|c|}{ ICS only $(n=5419)$} \\
\hline & Events & Hazard ratio & Events & Hazard ratio $(95 \% \mathrm{Cl})$ & Events & Hazard ratio $(95 \% \mathrm{Cl})$ \\
\hline Hospitalization & 50 & 1.00 & 10 & $0.54(0.27-1.07)$ & 59 & $0.81(0.55-1.19)$ \\
\hline All control failures & 198 & 1.00 & 51 & $0.81(0.59-1.11)$ & 236 & $0.93(0.76-1.12)$ \\
\hline
\end{tabular}

Cox proportional hazards model (hazard ratios and $95 \% \mathrm{Cl}$ ) for the first 30 days of follow-up after prescription. Use of leukotriene receptor antagonists ( $L$ TRA) is the reference; hazard ratios are adjusted for the number of physician visits, diagnostic group and drug use in the two years before the index claim. ICS Inhaled corticosteroids

As expected, we found that the prescription of LTRA was most common for patients with a diagnosis of asthma, although $5 \%$ had COPD and $7.4 \%$ had no physician claims for a respiratory diagnosis in the prior two years (one-half of the latter group received a second prescription). Patients that received LTRA had relatively high physician visit rates and a high use of other respiratory drugs. We interpret this as indicating that they were thought to have relatively severe disease by their physicians, although this is apparently contradicted by the fact that LTRA recipients were less likely to receive beta-agonists (Table 1 ). This was true in patients with asthma, and it appeared that beta-agonist use was associated with better, not worse, control. Others have reported that LTRA use is associated with asthma severity (12). This is not surprising because most physicians consider a change of or addition to therapy when faced with a symptomatic patient. Of LTRA recipients, 35\% had a prescription for ICS within 60 days before receiving LTRA, so the latter appeared to be add-on therapy to ICS, as recommended by current guidelines $(5,6)$.

Patients were more likely to receive a first prescription for LTRA if they lived in a rural location. This was surprising because a previous study (13) of new drug prescribing found that rural or remote locations were associated with lower utilization rates. It may also have implied that LTRA were more likely to have been prescribed by general practitioners than by specialists, who are largely confined to the urban area. This prescribing pattern may have reflected the efforts of pharmaceutical representatives, who are an important source of information on new drugs for general practitioners $(14,15)$. 
One-third of patients did not receive a second prescription for LTRA. This agrees with another study (16) that found a 31\% rate of failure to receive second prescriptions for LTRA. A cohort study of claims data in patients on either LTRA or ICS also showed better treatment adherence in the LTRA group (17). It is generally thought that compliance is better with oral than with inhaled medications $(10,18,19)$. The likelihood of filling a second prescription was perhaps related to disease severity, as indicated by the frequency of physician visits and the use of other respiratory drugs, but was not related to hospitalization.

Rural residence favoured the initial prescription of LTRA, but not the second. The failure to fill a second prescription may not indicate poor compliance because many patients may not have perceived a symptomatic benefit from the drugs and/or had self-limited disease as opposed to chronic asthma.

Of patients that received more than a single prescription, one-half received more than five over the subsequent year. Patients of all age groups who received more than five LTRA prescriptions had previously had greater use of other respiratory medications and more treatment failures than those who received fewer LTRA prescriptions (Tables 2 and 3). This suggests that continued LTRA use was associated with more severe asthma. In the year that they received LTRA, patients who regularly used the drugs showed a decrease in ICS use and failure rate, including hospitalizations; this finding was largely observed in the pediatric age group (Tables 2 and 3). Persistent LTRA use improved asthma control, especially in children, as shown in clinical trials (20-23).

\section{REFERENCES}

1. Hay DW, Trophy TJ, Undem BJ. Cysteinyl leukotrienes in asthma: Old mediators up to new tricks. Trends Pharmacol Sci 1995;16:304-9.

2. Laitinen LA, Laitinen A, Haahtela T, Vilkka V, Spur BW, Lee TH. Leukotriene E4 and granulocytic infiltration into asthmatic airways. Lancet 1993;341:989-90.

3. Drazen JM, Israel E, O'Byrne PM. Treatment of asthma with drugs modifying the leukotriene pathway. N Engl J Med 1999;340:197-206.

4. Laviolette M, Malmstrom K, Lu S, et al. Montelukast added to inhaled beclomethasone in treatment of asthma. Am J Respir Crit Care Med 1999;160:1862-8.

5. Boulet LP, Becker A, Berube D, Beveridge R, Ernst P. Canadian Asthma Consensus Report, 1999. Canadian Asthma Consensus Group. CMAJ 1999;161(Suppl 11):S1-S61.

6. British Thoracic Society; Scottish Intercollegiate Guidelines Network. British guideline on the management of asthma. Thorax 2003;58(Suppl 1):i1-94.

7. National Institutes of Health Global Initiative for Asthma. Global strategy for asthma management and prevention. 2005 update. $<$ http://www.ginasthma.com> (Version current at February 8, 2006).

8. WHO Collaborating Centre for Drug Statistics Methodology. Guidelines for ATC Classification and DDD Assignment. Oslo: Norwegian Institute of Public Health, 1995.

9. International Classification of Diseases, 9th Revision. Geneva: World Health Organization, 1978.

10. Kelloway JS, Wyatt RA, Adlis SA. Comparison of patients' compliance with prescribed oral and inhaled asthma medications. Arch Intern Med 1994;154:1349-52.

11. McFadden ER Jr. Acute severe asthma. Am J Respir Crit Care Med 2003; 168:740-59.

12. Snyder L, Blanc PD, Katz PP, Yelin EH, Eisner MD. Leukotriene modifier use and asthma severity: How is a new medication being used by adults with asthma? Arch Intern Med 2004;164:617-22.

13. Tamblyn R, McLeod P, Hanley JA, Girard N, Hurley J. Physician and practice characteristics associated with the early utilization of new prescription drugs. Med Care 2003;41:895-908.
We attempted to assess the further impact of LTRA on treatment failures by examining the time to such events. We chose to look at 30 days initially because we believed it likely that patients actually used the drugs immediately after they were prescribed. No significant difference was found in time to treatment failure among patients given LTRA, ICS, or both; however, there was a tendency for those receiving both to have better outcomes. Failure rates over one year were apparently unrelated to contemporary drug use. A systematic review of randomized controlled trials comparing LTRA with ICS as monotherapy for 28 days or more in both adults and children with asthma found similar results (24). Patients who received LTRA were $60 \%$ more likely to suffer an exacerbation requiring systemic corticosteroids than those who received ICS, and they were 2.5 times more likely to discontinue treatment due to poor asthma control. A similar systematic review of randomized controlled trials evaluating the effect on asthma exacerbations of LTRA taken daily for 28 days or more as an add-on therapy for current users of ICS found a nonsignificant reduction in the risk of exacerbations requiring systemic corticosteroids ( $\mathrm{RR}=0.61,95 \% \mathrm{CI} 0.36$ to 1.05$)$ (21).

\section{CONCLUSIONS}

We conclude that on introduction, LTRA were given to patients with evidence of relatively severe disease, and that compliance with treatment in these patients was associated with evidence of benefit, as seen in clinical trials; however, compliance was too low to observe benefits in unselected cohorts.

14. Jones MI, Greenfield SM, Bradley CP. Prescribing new drugs: Qualitative study of influences on consultants and general practitioners. BMJ 2001;323:378-81.

15. Volovitz B, Friedman N, Levin S, et al. Increasing asthma awareness among physicians: Impact on patient management and satisfaction. J Asthma 2003;40:901-8.

16. Jones C, Santanello NC, Boccuzzi SJ, Wogen J, Strub P, Nelsen LM. Adherence to prescribed treatment for asthma: Evidence from pharmacy benefits data. J Asthma 2003;40:93-101.

17. Bukstein DA, Henk HJ, Luskin AT. A comparison of asthma-related expenditures for patients started on montelukast versus fluticasone propionate as monotherapy. Clin Ther 2001;23:1589-600.

18. Bukstein DA, Bratton DL, Firriolo KM, et al. Evaluation of parental preference for the treatment of asthmatic children aged 6 to 11 years with oral montelukast or inhaled cromolyn: A randomized, open-label, crossover study. J Asthma 2003;40:475-85.

19. Bukstein DA, Luskin AT, Bernstein A. "Real-world" effectiveness of daily controller medicine in children with mild persistent asthma. Ann Allergy Asthma Immunol 2003;90:543-9. (Erratum in 2003;91:308).

20. Dempsey OJ, Fowler SJ, Wilson A, Kennedy G, Lipworth BJ. Effects of adding either a leukotriene receptor antagonist or low-dose theophylline to a low or medium dose of inhaled corticosteroid in patients with persistent asthma. Chest 2002;122:151-9.

21. Ducharme FM. Anti-leukotrienes as add-on therapy to inhaled glucocorticoids in patients with asthma: Systematic review of current evidence. BMJ 2002;324:1545-52.

22. Price DB, Hernandez D, Magyar P, et al. Randomised controlled trial of montelukast plus inhaled budesonide versus double dose inhaled budesonide in adult patients with asthma. Thorax 2003;58:211-6.

23. Vaquerizo MJ, Casan P, Castillo J, et al. Effect of montelukast added to inhaled budesonide on control of mild to moderate asthma. Thorax 2003;58:204-10. (Erratum in 2003;58:370).

24. Ducharme FM. Inhaled glucocorticoids versus leukotriene receptor antagonists as single agent asthma treatment: Systematic review of current evidence. BMJ 2003;326:621-5. 


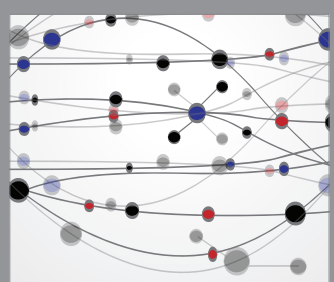

The Scientific World Journal
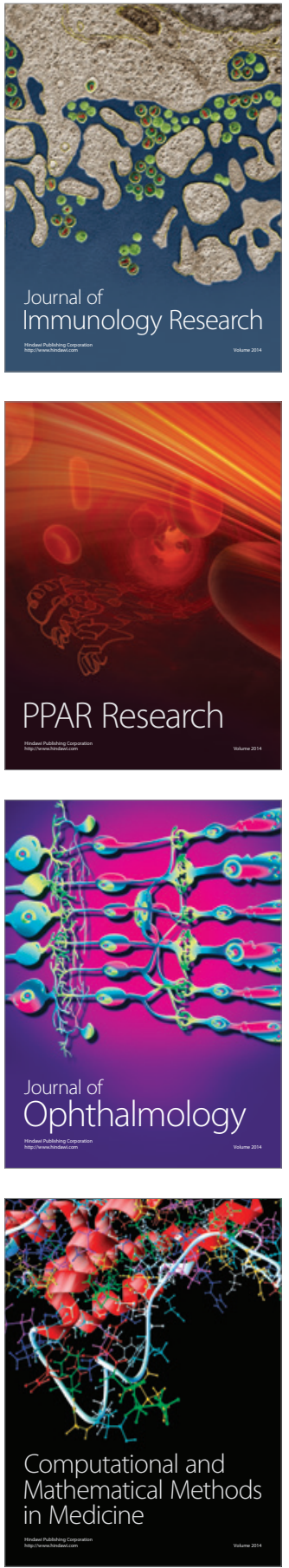

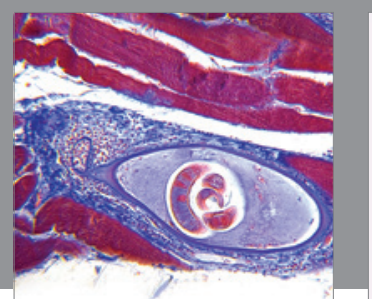

Gastroenterology Research and Practice

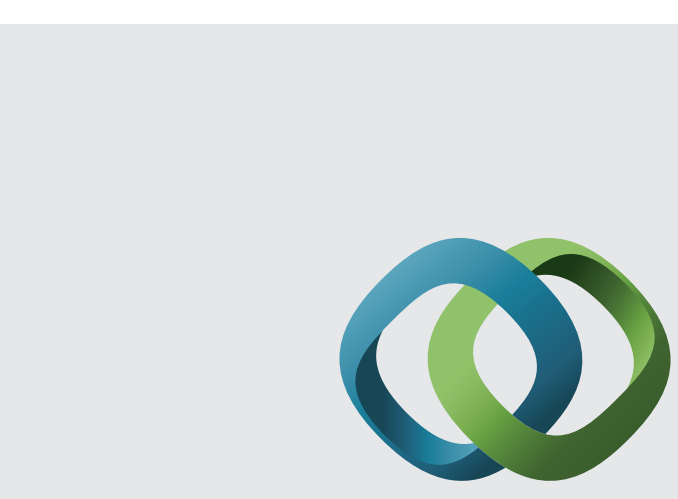

\section{Hindawi}

Submit your manuscripts at

http://www.hindawi.com
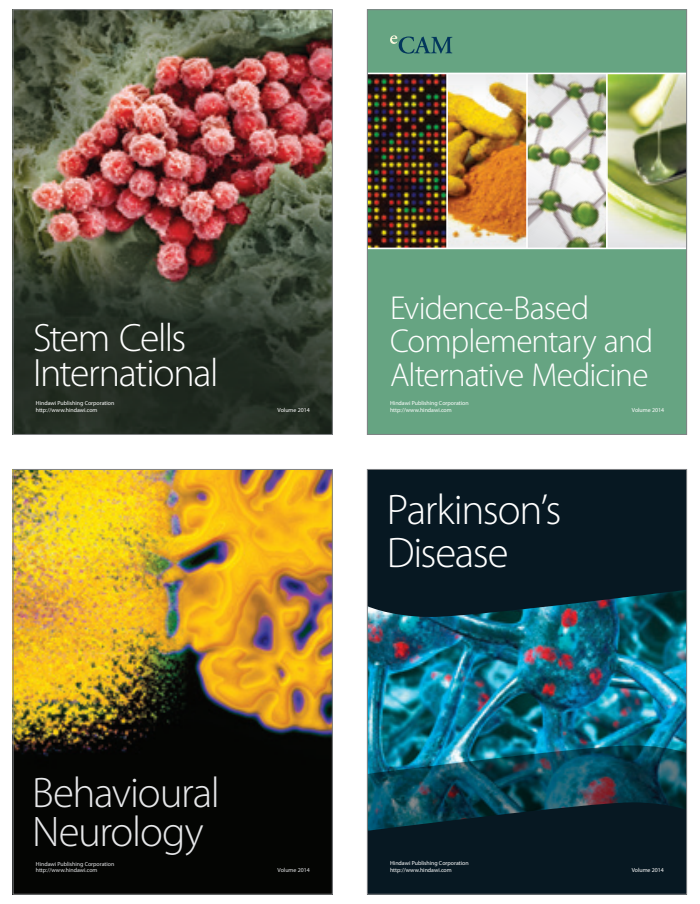
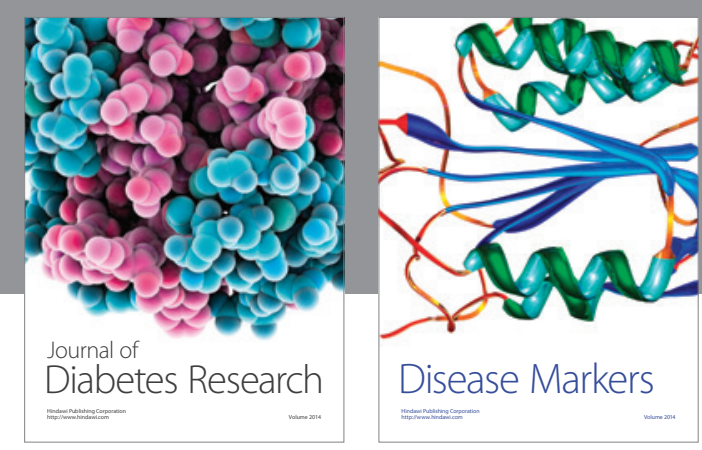

Disease Markers
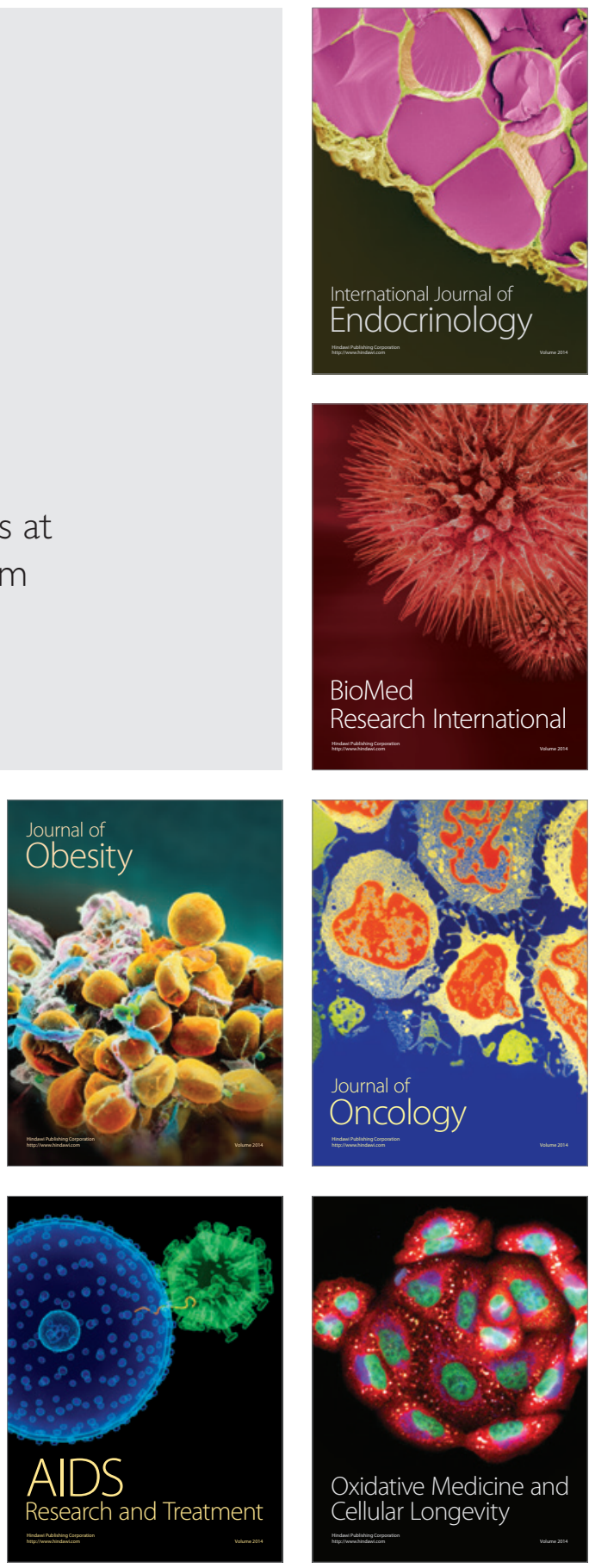